\title{
Development Processes of Globular Microstructure
}

\author{
A.V. Adedayo ${ }^{1,2}$ \\ ${ }^{1}$ Department of Materials Science and Engineering, Obafemi Awolowo University, Ile-Ife, \\ Nigeria \\ ${ }^{2}$ Department of Metallurgical Engineering, Kwara State Polytechnic, PMB 1375, Ilorin, \\ Nigeria \\ e-mail: victor.adedayo@kwarapolytechnic.com
}

\begin{abstract}
Semi solid metallurgy offers distinct advantages over other near-net-shape manufacturing processes. By this process, components are produced from slurry kept at a temperature between the solidus and the liquidus isotherms, resulting in breakdown of the dendritic structure. A new structure in which the morphology of the crystals of the primary phase is globular evolves. In this present paper, the importance of globular structure is identified. The theories of evolution of globular crystals in thixo - processing are identified and discussed.
\end{abstract}

Keywords: Semi solid metallurgy, globular crystals, thixo-processing

\section{INTRODUCTION}

Semi solid metallurgy (SSM) is of growing industrial significance particularly for the low melting alloys [1]. Although SSM is already a viable manufacturing method, it is still under intensive development and critical breakthroughs are still much expected [2]. The production of SSM feedstock is of considerable interest and current research effort is concentrated on production of feedstock alloys where the primary phase in the microstructure consists of globularized particles [3-6]. This is one of the needed requirements for semi solid metallurgy feedstock $[2,3,7]$.

The belief that the utilization of SSM as a manufacturing process follows from the generally accepted advantages of hardware performance and energy economy is apparently a simplification. Also, the influence of globular structure on the component integrity is complex. In general, microstructure affects components properties [8-10]. For the semi solid 
components, product integrity is affected through a reduction in porosity. The turbulent flow of a liquid into a mould can result in the entrapment of air and mould gases into the melt, which in turn may translate into micro- and macro-porosity. Smooth flow of the semi-solid slurry minimizes these defects. Similarly, segregation and shrinkage porosity are affected. All these: flow behaviour, segregation and solidification shrinkage depend on the nature of the globular microstructure of the SSM component.

To assess morphological details of a globular structure, shape factor and sphericity are parameters which are very prominent and stick out. For single crystal, the size of which is defined by some length parameter or equivalent diameter, $d$, and density, $\rho$ the following relationships can be applied:

$\begin{array}{ll}\text { Volume } & v=f_{y} d^{3} \\ \text { Mass } & m=f_{y} \rho d^{3} \\ \text { Surface area } & s=f_{s} d^{2}\end{array}$

The constants $f_{v}$ and $f_{s}$ may be called volume and surface shape factors respectively [11]. For spherical (diameter $=\mathrm{d}$ ) and cubic (length of side $=\mathrm{d}$ ) particles

$$
\begin{array}{ll}
f_{y}=\pi / 6 & \text { (Sphere) and } 1 \text { (cube) } \\
f_{s}=\pi & \text { (Sphere) and } 6 \text { (cube) }
\end{array}
$$

The shape factors are readily calculated for other regular geometrical solids. The other prominent quantity that has been used to characterize phase morphology in microstructures is the sphericity, $\psi$, defined as the ratio of the surface area of a sphere having the same volume as the phase to the apparent estimated surface area of the phase [11]. This can be rewritten as

$$
\psi=\frac{\left(6 f_{v} / \pi\right)^{2 / 3}}{f_{s} / \pi}
$$

For isometric shapes $\psi$ is close to 1 while for needles or platelets its value is much lower. Evaluation of $\psi$ is useful for checking the values of $f_{v}$ and $f_{s}$ since $0<\psi<1$.

In general, the influence of globular microstructure on the direction of changes of alloy properties is not universally positive and should be evaluated for individual alloy chemistry. The understanding of the theories of development of globular crystal is vital and useful for SSM process designs and other engineering applications. It will also provide insight on fundamentals for achieving the much expected breakthroughs in SSM.

\section{METHODS FOR PRODUCING GLOBULAR CRYSTALS}

Under conventional solidification conditions, dendritic microstrutres result [3]. This process is well discussed in literatures $[12,13]$. The process of producing globular crystals in metallic 
alloys which is suitable for SSM was commonly believed to rely upon the fragmentation of the secondary dendrite arms during solidification [3, 14]. A number of technologies have been developed over the last three decades, mainly in a laboratory environment, to take advantage of the unique behavior of semi-solid slurries to produce globular crystals. All the technologies can be divided into two fundamentally different basic routes: thixo-processing and rheo-processing. There are also hybrids that combine features of both routes.

\subsection{Thixo-Processing}

The thixo-route involves two stages: first, billet preparation and, second, billet re-heating and isothermal holding within the mushy zone of the alloy. The crystals which form in the process of conventional solidification of a metal have structures which are dendritic, lamellar or fibrous, needle type (acicular) or globular, depending on the rate of cooling and the type and amount of admixtures or impurities (intermetallics) in the melt [13]. Perfect crystals of proper external shape can be obtained only if crystallization develops under condition when the degree of super cooling is very slight and the metal has a very high purity [13]. In great majority of cases, branched or tree-like crystals are obtained which are called dendrites. Figure 1 shows steps in the formation of a dendritic crystal.

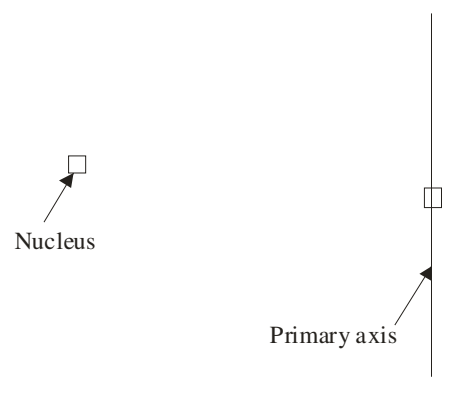

(a)

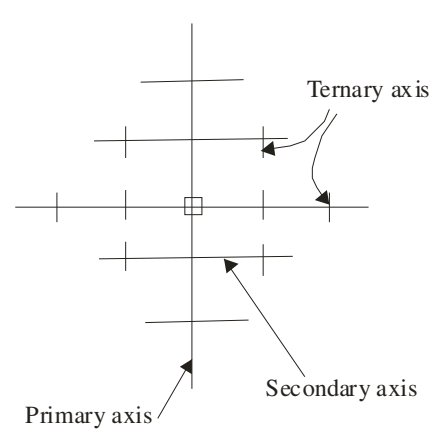

(d)

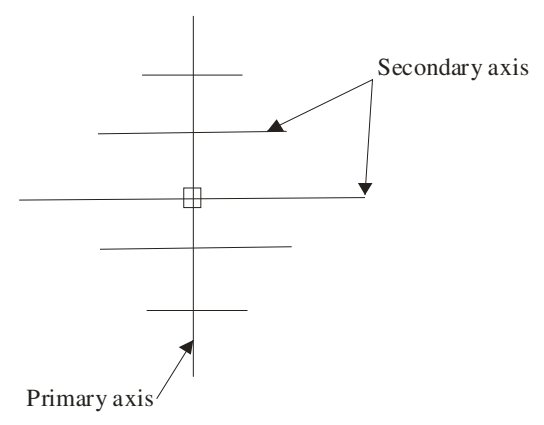

(c)

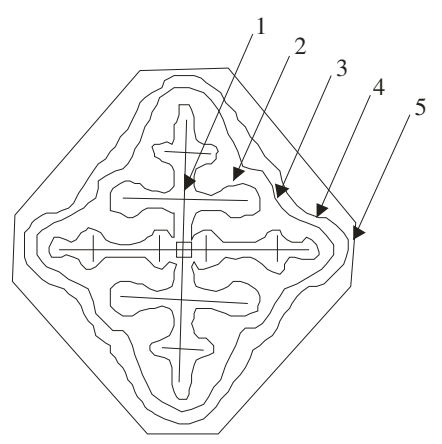

(e)

Figure 1: Formation of dendritic crystals [1, 13] . 
A crystal nucleus forms as shown in (a) and then proceeds to send out shoots or axis of solidification as shown in (b), (c), (d) forming the skeleton of a crystal. Atoms then attach themselves to the axes of the growing crystal from the melt in progressive layers (layers 1, 2, 3, 4 and 5 as shown in Fig. 1e), finally filling up these axes, and thus forming a completed solid crystal.

However, during billet re-heating thixo-processing of the metallic alloy there is partial melting of the structures in the alloy. These may be any of the various compounds found in the alloy. Constituents with low melting points melt into liquid. Also, as the temperature rises, there is break-up of the primary and secondary axis into smaller unit [1], and random re-orientation of the break-up network. Due to high diffusion rates in the mushy zone, atoms of the melted constituents diffuse from the liquid phase and joined up with the existing solid crystals. This phenomenon leads to evolution of new structure which is globular. This process is shown in Fig. 2.
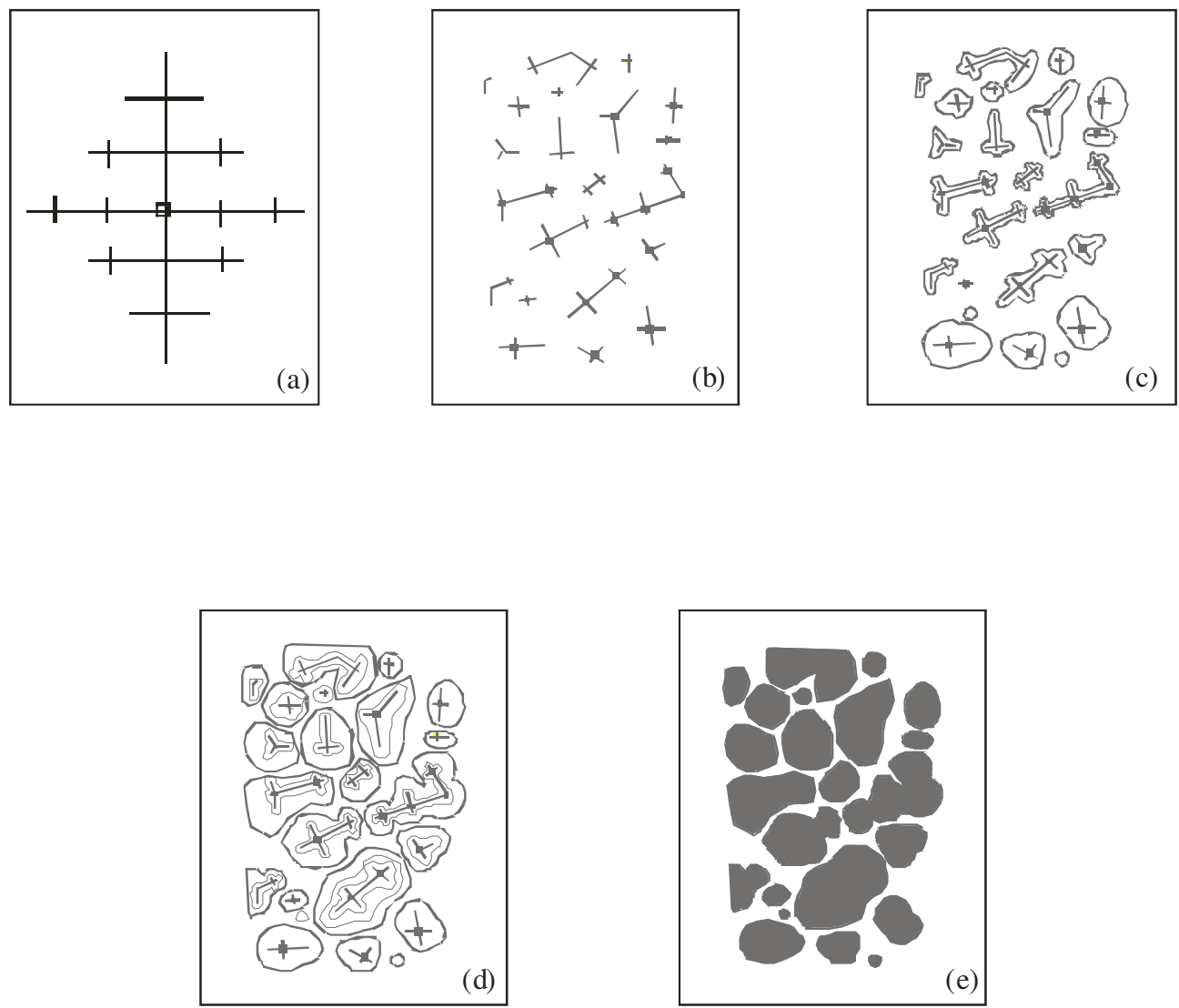

Figure 2: Development of globular structure (a) dendritic structure formed during solidification in a casting (b) breakdown of dendritic network to form new nuclei during semi solid isothermal heating, (c), (d) and (e) the process of emergence of globular structure [1]. 


\section{TEMPERATURE AND GLOBULAR MORPHOLOGY}

In conventional castings, the material in the interior of the ingot cools more slowly, and solidification takes place at a higher temperature. Usually, some of the grains near the surface simply grow inwards as heat flows outwards. The resulting structure is columnar (illustrated in Fig. 3). The columnar grains are not randomly oriented but rather have their directions of most rapid growth normal to the mould walls, which is the direction of heat withdrawal. In general, crystals grow in certain directions depending on some factors such as direction of heat flow and presence of impurities.

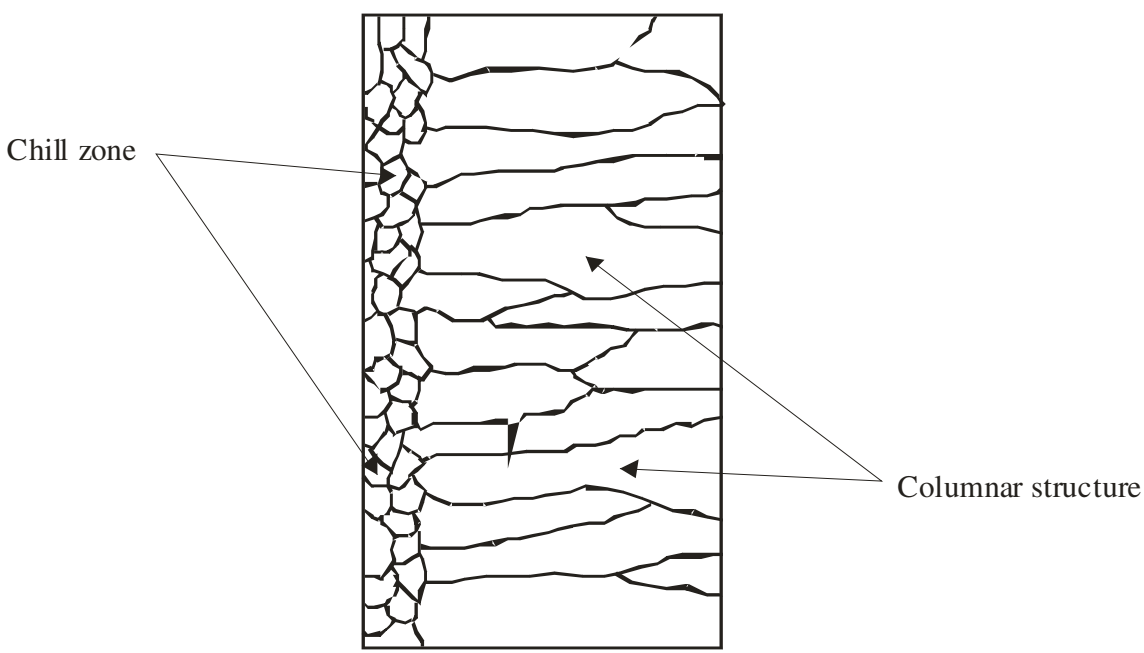

Figure 3: Sketch of chill zone and columnar structure in conventional casting

The direction of heat flow is a function of the temperature field. In mathematical physics, the temperature field is the totality of temperature values at a given point in time for all points of the space considered in which heat transfer process takes place. During solidification, the temperature at various points change with time and heat propagates from places at a higher temperature to places at lower temperature. It follows that during solidification, there is variation of temperature both in space and time. If the temperature of a body is a function of space coordinates and time, the temperature field is referred to as transient kind. i.e.

$$
T=f(x, y, z, t) ; \frac{\partial T}{\partial t} \neq 0
$$

where $\mathrm{x}, \mathrm{y}, \mathrm{z}$ are point coordinates, $\mathrm{t}$ is the time. If the temperature of a body is a function of space coordinates only and does not vary with time, the temperature field is referred to as a steady state i.e.

$$
T=f(x, y, z, t) ; \frac{\partial T}{\partial t}=0
$$


The nature of the temperature field also determines the temperature gradient.

For alloy materials, when the grain boundary grooving occurs such that the boundary intersects the liquid-solid interface, the curvature in the neighborhood of the groove is determined by the requirement that [15]:

$$
T^{*}=T_{m}-G \Delta X=T_{m}-\Delta T_{r}
$$

Where $T^{*}$ is the liquid-solid interface temperature, $\mathrm{G}$ is the thermal gradient and $\Delta \mathrm{X}$ is the distance back from the isotherm at $\mathrm{T}_{\mathrm{m}}$, the equilibrium melting point of the alloy material (the liquidus temperature ).

But also,

$$
\begin{aligned}
& \Delta G_{L}=S_{L} \Delta T_{r} \\
& \Delta G_{s}=S_{s} \Delta T_{r}+2 V_{s} \sigma \lambda
\end{aligned}
$$

Where $\Delta \mathrm{G}_{\mathrm{L}}$ and $\Delta \mathrm{G}_{\mathrm{s}}$ are the changes in free energies of liquid and solid, respectively. $\mathrm{Vs}$ is the volume of the solid, $\lambda$ is the surface curvature in the groove neighborhood, $T_{r}$ is the decrease in equilibrium melting point, $\sigma$ is the surface energy of the interface. Assuming that $\sigma$ is isotropic and does not change as surface area changes, at equilibrium [15]:

$$
\Delta G_{L}=\Delta G_{s}
$$

It follows that:

$$
\begin{aligned}
& S_{L} \Delta T_{r}=S_{s} \Delta T_{r}+2 V_{s} \sigma \lambda \\
& \left(S_{L}-S_{s}\right) \Delta T_{r}=2 V_{s} \sigma \lambda \\
& S_{L}-S_{s}=-\Delta S \\
& \Delta T_{r}=\frac{2 V_{s} \sigma \lambda}{\Delta S} \\
& \Delta S=\frac{\Delta H}{T_{m}} \\
& \Delta T_{r}=\frac{-2 T_{m} V_{s} \sigma \lambda}{\Delta H}
\end{aligned}
$$

But: $\quad \Delta T_{r}=G \Delta X$

$$
\begin{aligned}
& G \Delta X=\frac{-2 T_{m} V_{s} \sigma \lambda}{\Delta H} \\
& \frac{1}{\lambda}=\frac{-2 T_{m} V_{s} \sigma \lambda}{G \Delta X \Delta H}
\end{aligned}
$$

But the curvature $\lambda$ at a point is described as the limit (provided it exists) of the average 
curvature $\lambda_{\mathrm{av}}$ of an arc as the terminal point of the arc tends to its initial point [16]. For arc $\mathrm{M}_{0} \mathrm{M}_{1}$, as the terminal point of the arc $\mathrm{M}_{1}$ tends to its initial point $\mathbf{M}_{0 \text { : }}$

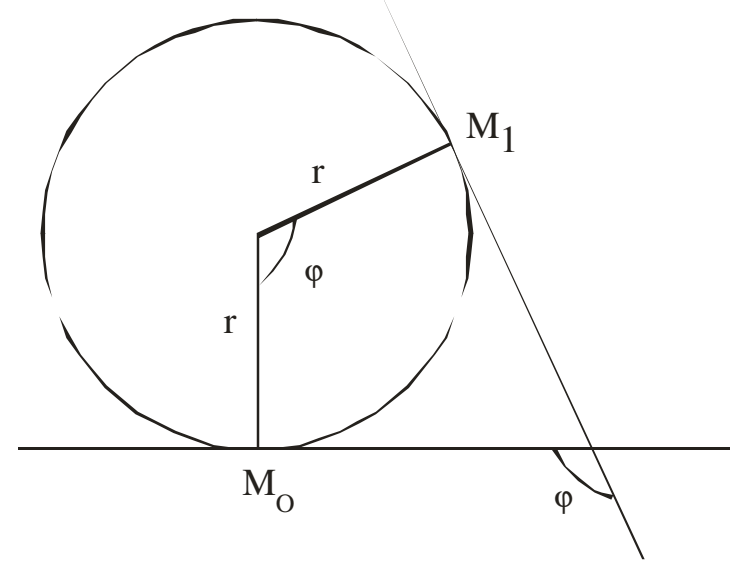

Figure 4: Geometric description of relationship between $r, \varphi$ and curvature $(\lambda)$

$$
\lambda=\operatorname{Lim}_{\mathrm{M}_{1} \rightarrow \mathrm{M}_{0}} \lambda_{\mathrm{av}}=\operatorname{\mathrm {Mim}}_{1 \rightarrow \mathrm{M}_{0}}\left(\varphi / \mathrm{M} 0 \mathrm{M}_{1}\right)
$$

Where $\varphi$ is the angle of contingence of the arc (in radians).

So; $\quad \mathrm{M}_{0} \mathrm{M}_{1}=\mathrm{r} \varphi$

Thus;

$$
\operatorname{Lim}_{M_{1 \rightarrow M_{0}}}\left(\varphi / M_{0} M_{1}\right)=\varphi / r \varphi=1 / r
$$

Therefore: $\quad \lambda=1 / \mathrm{r}$

Then: $\quad r=\frac{-2 T_{m} V_{s} \sigma \lambda}{G \Delta X \Delta H}$

The thermal gradient $G$ will depend on the thermal stability of the furnace used [17], and in general the temperature field during thixo-processing. If the temperature field of the system is transient the thermal gradient $\mathrm{G}$ will depend on time and space coordinate. The value of $r$ will vary with time. Transient temperature fields are experienced during heating and cooling of a system. However, for isothermal heating, the temperature field is steady. Temperature gradient $\mathrm{G}$ will be essentially constant and independent of time. This gives an essentially constant value for $r$. This results in a spheriodal morphology. This shows that the ability of the heat treatment furnace to maintain an efficient steady-state will affect the morphology of the evolving crystal. Also, value of $G$ (whether $G<0$ or $G>0$ ) will affect the concavity or convexity of the resulting crystal. 


\section{CONCLUSION}

The study revealed that globular microstructure evolves as a result of breakdown of dendritic structure during thixo-processing of the conventionally cast materials. The effect of temperature field and thermal gradient of the heating furnace has also been shown to have influence on the morphology of the evolved microstructure.

\section{REFERENCES}

[1] Adedayo, A.V. 2009 Basics and Benefits of Semi-Solid Metallurgy, Journal of Research in Technology and Engineering Management, Vol. 2, No. 1 pp25-29

[2] Czerwinski F. 2008a The basics of modern SSMP. Journal of the Minerals, Metals and Materials Society, Vol. 58, No.6, pp. 17-20

[3] Browne D.J.; M.J. Hussy; A.J. Carr; D. Brabazon 2003 Direct thermal method: new process for development of globular alloy microstructure; International Journal of Cast Metals Research, Vol.16, No 4, pp 418-426.

[4] Reisi M., Niroumand B., 2008 Effects of stirring parameters on rheocast structure of Al-7.1wt pet Si alloy, Journal of Alloys and Copounds, Vol 32, No. 1, pp 41-47

[5] Margarido M., Robert M.H. (2003) The production of alloys with rheocast structure, Journal of Brazilian society of mechanical science and engineering. Vol 25, Issue: 2. pp 207-214

[6] Paes M., Santos E.G., Zoqui E.J. 2006 Obtention rheocast structure for Al-4.5wt\% Cu alloy: comparison ultra-refining and electromagnetic stirring, JAMME, Vol 9, No 2, 21-27

[7] Czerwinski F. 2008b Fundamentals of semisolid magnesium. Journal of the Minerals, Metals and Materials Society, Volume 60, Number 11, pp. 82-86

[8] Adedayo, A.V. 2010 Effects of Addition of Iron Filings to Green Moulding Sand on the Microstructure of Grey Cast Iron. Journal of the Brazilian society for Mechanical Sciences and Engineering, Vol. XXXII, No 2, pp 171-175

[9] Adedayo, A.V., Ibitoye, S.A., Oyetoyan, O.A. 2010 Annealing Heat Treatment Effects on Steel Welds. Journal of Mineral, Materials Characterization and Engineering, Vol. 9, No. 6 pp 547-557.

[10] Ibitoye S. A., Shittu M. D., Olawale J. O., (2010) Grain size and porosity of cast hypoeutectic aluminum-silicon alloys in hexachloroethane coated mould, Russian Journal of Non-Ferrous Metals, Volume 51, No 1, pp 62-68

[11] Mullin J.W., 2001 Crystallization, $4^{\text {th }}$ ed., Oxford, London, pp 74, 75

[12] Kurz W.; Fisher D.J. 1998 Fundamentals of solidification, $4^{\text {th }}$ ed. Aedermannsdorf Transactions Technical publications.

[13] Rajput R.K. (2006) Engineering materials and metallurgy, $1^{\text {st }}$ ed. S. Chand \& Co. New Delhi., pp 25, 26,27, 28

[14] Doherty R.D.; Lee H.; Feest E.A. 1984 Particle shape analysis in Rheocast Aluminum Copper systems, Material science and engineering, 65, pp 181-189

[15] Fleming, M.C. 1974 Solidification processing, Materials science and engineering series, McGraw-Hill, New York, pp 162, 273, 286. 
[16] Bermant, A.F.; Aramanovich, I.G. 1989 Mathematical analysis, A brief course for engineering students, Mir publishers, Moscow, pp 222, 223

[17] Oluwole, O.O.; Atanda, P.O.; Imasogie, B.I. 2009 Finite element modeling of heat transfer in salt bath furnaces, Journal of Minerals and Materials Characterization and Engineering, Vol. 8, No. 3, pp 229-236 